\title{
AGRESSÕES AO DIREITO FINANCEIRO DÃO RAZÕES PARA O IMPEACHMENT
}

Coluna publicada em 5.4.2016: <https://www.conjur.com.br/2016-abr-05/ contas-vista-agressoes-direito-financeiro-dao-razoes-impeachment $>$

Nunca antes na história deste País o Direito Financeiro esteve tão em evidência, mas as razões que levaram a isso não são motivo de comemoração. $\mathrm{O}$ contumaz descumprimento das normas de Direito Financeiro que se tem observado nos últimos anos, e que agora é o principal fundamento do pedido de impeachment da Presidente da República ora sob análise da Câmara dos Deputados, trouxe esse ramo do Direito para o centro do debate, que se acirra essa semana, quando se aproxima a definição de importante etapa do processo, com a apresentação da defesa ${ }^{1} \mathrm{e}$ decisão do Congresso Nacional.

Momento oportuno para que sejam esclarecidos vários pontos no âmbito do Direito Financeiro que estão sendo discutidos com intensidade nesses últimos dias.

A petição inicial ${ }^{2}$ firmada pelos juristas Hélio Bicudo, Miguel Reale Júnior, Janaína Paschoal e Flávio Pereira, contendo denúncia em face da Presidente Dilma Rousseff pela prática de crime de responsabilidade, com o pedido de decretação da perda do cargo e inabilitação para exercer função pública por oito anos, descreve condutas que são diretamente relacionadas ao Direito Financeiro, e sobre as quais é relevante esclarecer e informar, ainda que de forma sucinta, dadas as limitaçôes deste espaço.

Sobre os decretos ilegais de abertura de créditos suplementares, a denúncia imputa à Presidente da República os crimes de responsabilidade tipificados na Lei

1 Esta coluna foi escrita antes de ser apresentada a defesa da Presidente.

2 Datada de 15.10.2015, com o respectivo aditamento. 
1.079/1950, art. 10, itens $4,{ }^{3} 5^{4}$ e $6,{ }^{5}$ por ter editado decretos não numerados para abrir créditos suplementares sem autorização legal, da ordem de 18 bilhões de reais.

As condutas descritas foram apuradas, constatadas e reconhecidas como ilegais pelo Tribunal de Contas da União, em decisão tomada na sessão de 7 de outubro de 2015 (Acórdão 2.461/2015 - Plenário), na qual emitiu parecer pela rejeição das contas de governo referentes ao exercício de 2014. Como os fatos se repetiram em 2015, conforme descreve a denúncia, os esclarecimentos a seguir são feitos com base nesse último ano.

A lei orçamentária contém a previsão de receitas e a autorização de gastos, que, em face de alterações nas circunstâncias de fato ocorridas na execução orçamentária, podem ser modificadas, desde que com autorização legal.

A lei orçamentária federal de 2015 (Lei 13.115, de 20.4.2015), em seu art. 7º, concedeu autorização prévia para que o Poder Executivo editasse decretos abrindo créditos suplementares, mas condicionados à observância dos requisitos fixados, entre os quais está a necessidade de compatibilização com as metas de resultado primário. ${ }^{6}$

Referidas metas de resultado primário estão na Lei de Diretrizes Orçamentárias - no caso, a Lei 13.080, de 2.1.2015 -, que estabeleceu as diretrizes para o exercício de 2015. Esta lei definiu a meta de superávit primário no montante de 66 bilhōes de reais (art. $2^{\circ}$ ). Os relatórios de execução orçamentária produzidos no período de edição dos decretos atacados já mostravam a inviabilidade do cumprimento da meta, fato reconhecido pelo próprio governo, ao encaminhar projeto de lei propondo a alteração da LDO vigente, ante a constatação da frustração de receitas e elevação das despesas. Evidentemente, as condiçôes para a abertura dos créditos suplementares devem estar presentes no momento da respectiva abertura. Sendo assim, os decretos aludidos na denúncia foram baixados em desacordo com

3 "Infringir, patentemente, e de qualquer modo, dispositivo da lei orçamentária."

4 "Deixar de ordenar a redução do montante da dívida consolidada, nos prazos estabelecidos em lei, quando o montante ultrapassar o valor resultante da aplicação do limite máximo fixado pelo Senado Federal."

5 "Ordenar ou autorizar a abertura de crédito em desacordo com os limites estabelecidos pelo Senado Federal, sem fundamento na lei orçamentária ou na de crédito adicional ou com inobservância de prescrição legal.”

6 "Fica o Poder Executivo autorizado a abrir créditos suplementares, observados os limites e condiçôes estabelecidos neste artigo, desde que as alteraçōes promovidas na programação orçamentária sejam compatíveis com a obtenção da meta de resultado primário estabelecida para o exercício de 2015 (...).” 
a autorização prevista na lei orçamentária, pois editados sem a observância dos requisitos fixados, o que ocorreu mesmo após o reconhecimento de que a meta não seria atingida.

Tendo em vista que a apuração do resultado primário faz-se ao final do exercício financeiro, pouco antes de seu término foi proposta e aprovada a Lei 13.199, em 3.12.2015, modificando a LDO vigente, para fazer constar não mais uma meta de resultado primário de 66 bilhões, mas uma meta de resultado deficitário de 49 bilhões. ${ }^{7}$ Uma manobra cuja única finalidade foi, inequivocamente, afastar formalmente a ilegalidade dos decretos, que, embora editados sem observar os requisitos legais à época da sua publicação, no final do exercício passam a estar de acordo com as metas posteriormente fixadas. Desnecessários argumentos mais densos para demonstrar que se trata de uma fraude, que está em desacordo com todos os princípios de responsabilidade fiscal, não sendo admissível que se aceite como justificativa para afastar o reconhecimento da ilegalidade dos decretos. Diante do descumprimento evidente da regra, mudou-se a regra, e não a conduta - medida que só engana quem faz absoluta questão de ser enganado.

Importa em anular por completo as funções da LDO e da lei orçamentária, e deixar de reconhecer seu caráter sistêmico no ordenamento jurídico, para dar crédito a um argumento que se afasta completamente das mais comezinhas regras de interpretação, exigindo que essas leis sejam inteiramente descontextualizadas do sistema de planejamento orçamentário da ação governamental.

Integram a denúncia também as "pedaladas fiscais", apelido que se convencionou atribuir à "prática recorrente de atrasar o pagamento de serviços prestados por fornecedores do setor público, atrasos no repasse dos ministérios setoriais para que bancos públicos e privados paguem os benefícios sociais e postergação no pagamento de subsídios devido a bancos públicos". ${ }^{8}$

Tais fatos, denunciados pelo Ministério Público de Contas, foram identificados e apurados pelo Tribunal de Contas da União, no exercício de sua competência de fiscalizar a atividade financeira da administração pública federal, que, em decisão tomada em 7.10.2015 (Acórdão 2.461/2015 - Plenário), emitiu parecer pela

7 Assunto já abordado na coluna 2015: o ano de triste memória para o Direito Financeiro que não quer terminar, publicada em 15 de dezembro de 2015 e que consta neste livro.

8 ALMEIDA, Mansueto. Pedaladas fiscais. Blog do Mansueto Almeida, <http://mansueto.wordpress.com/2014/08/29/pedaladas-fiscais/>, e sobre as quais já nos referimos na coluna Atenção caro leitor, pedalar faz mal à saúde!, publicada em 23 de setembro de 2014 e que consta neste livro. 
rejeição das contas de governo referentes ao exercício de 2014, por estarem comprovadas, entre outras irregularidades, a ocorrência destas "pedaladas fiscais", reconhecendo como operaçôes de crédito ilegais os adiantamentos concedidos pela Caixa Econômica Federal para despesas dos programas Bolsa Família, Seguro-Desemprego e Abono Salarial, bem como os adiantamentos concedidos pelo FGTS para despesas do Programa Minha Casa, Minha Vida.'

A defesa do governo à época, que pretendia ver reconhecidos esses atos não como operaçôes de crédito, e sim como meros fluxos de caixa, suprimento de fundos ou operações que representam prestações de serviços bancários, não foi acolhida, após análise técnica exaustiva e minuciosa por ocasião da apreciação das contas junto ao TCU. Os atrasos, como deixa claro o TCU no caso da CEF, "longe de se justificarem por necessidades de adequaçôes da dinâmica dos fluxos de desembolsos, redundaram na utilização da CEF como grande financiadora das políticas públicas de que tratam os benefícios em tela, por meio da realização de operações de crédito vedadas pela LRF", não tendo a instituição reconhecido os atos como rotineiros, tanto que recorreu à Câmara de Conciliação e Arbitragem da Administração Federal para solucionar a controvérsia. As movimentações financeiras representadas pelos atrasos sistemáticos no repasse de recursos do Tesouro Nacional às instituiçôes financeiras estatais, concluiu o TCU, "têm natureza jurídica de operação de crédito, independentemente do nomen juris que porventura lhe tenha sido atribuída, o qual obviamente não tem o condão de modificar a sua essência”." ${ }^{10}$

Essas condutas foram incluídas na denúncia por tipificarem crime de responsabilidade, descrevendo a peça inicial a ocorrência tanto no período analisado pelo TCU, como no exercício de 2015, neste último sob a forma de adiantamentos do Banco do Brasil em relação ao Plano Safra, de alongamento de crédito rural, em que se apuraram valores expressivos, da ordem de 3 bilhões de reais, devidos por equalização de taxa de juros. Imputa-se violação aos artigos 85, VI, da Constituição e 10, alíneas 6, 7, 8 e 9 da Lei 1.079/50. O artigo 85, VI, da Constituição tipifica como "crimes de responsabilidade os atos do Presidente da República que atentem contra a Constituição Federal e, especialmente, contra a lei orçamentária". A Lei 1.079/50, ao especificar as condutas dos respectivos crimes em seu art. 10, descreve, no item 6 , já referido, "Ordenar ou autorizar a abertura de crédito em

9 Tema já abordado em outras colunas, como a publicada em 30 de junho de 2015, Julgamento das contas do governo precisa ser feito com rigor, e Julgamento do TCU que reprovou contas do governo entrou para a história do Direito Financeiro, publicada em 20 de outubro de 2015. Ambas as colunas citadas constam neste livro.

10 TCU, Acórdão 2.461/2015, voto Min. Augusto Nardes. 
desacordo com os limites estabelecidos pelo Senado Federal, sem fundamento na lei orçamentária ou na de crédito adicional ou com inobservância de prescrição legal"; no item 7, "Deixar de promover ou de ordenar, na forma da lei, o cancelamento, a amortização ou a constituição de reserva para anular os efeitos de operação de crédito realizada com inobservância de limite, condição ou montante estabelecido em lei"; no item 8, "Deixar de promover ou de ordenar a liquidação integral de operação de crédito por antecipação de receita orçamentária, inclusive os respectivos juros e demais encargos, até o encerramento do exercício financeiro"; e no item 9, "Ordenar ou autorizar, em desacordo com a lei, a realização de operação de crédito com qualquer um dos demais entes da Federação, inclusive suas entidades da administração indireta, ainda que na forma de novação, refinanciamento ou postergação de dívida contraída anteriormente".

É denunciada ainda a Presidente pela prática do crime de responsabilidade previsto no art. 10, item 4 ("São crimes de responsabilidade contra a lei orçamentária infringir, patentemente, e de qualquer modo, dispositivo da lei orçamentária"), por irregularidades no registro de valores como dívida líquida do setor público, decorrentes das operações que integraram o rol das "pedaladas fiscais", causando distorções nas informaçôes da lei orçamentária e desvios na apuração do resultado fiscal, fato que também foi analisado pelo TCU na já citada decisão.

Não é segredo que este governo tem sido marcado - e não é de hoje - pela irresponsabilidade na gestão das finanças públicas, tantas vezes denunciada neste espaço. ${ }^{11}$ Desprezo e desrespeito às normas de finanças públicas são evidentes e têm sido constantes, e os danos causados estão aí para serem vistos. Isto não pode ser aceito pelos operadores, aplicadores e intérpretes do Direito. Nem relativizado, sob o argumento de que possam ter ocorrido desvios em outros períodos e entes da federação. Esta é uma oportunidade ímpar para rechaçar estas condutas reprováveis e mostrar que as normas de finanças públicas existem para serem cumpridas, e as consequências das suas violações são graves.

Outras imputações foram feitas, de natureza financeira e não financeira, que permitem o enquadramento em infraçóes de natureza penal, civil, administrativa e financeira, como já exposto em texto anterior. ${ }^{12}$ Há ainda outras denúncias,

11 Vide as colunas Contas "maquiadas" não vão tornar nosso país mais bonito, publicada em $12 \mathrm{de}$ fevereiro de 2013, O Direito Financeiro precisa ser levado a sério, e 2015 começou mal, publicada em 10 de fevereiro de 2015, Irresponsabilidade fiscal ainda persiste, 15 anos após a publicação da lei, publicada em 7 de abril de 2015, dentre outras. Todas elas constam neste livro.

12 Coluna Cuidado, pedalar pode dar cadeia!, publicada em 5 de maio de 2015 e que consta neste livro. 
como a recentemente protocolada pela $\mathrm{OAB}$, nas quais outras condutas apontadas como violadoras das normas de Direito Financeiro são descritas como crimes de responsabilidade. O espaço, no entanto, é curto, razão pela qual foram expostos apenas os fundamentos que justificam parte das acusações, a fim de permitir que seja possível conhecer melhor as razóes que podem levar a Presidente a perder seu cargo.

Convém deixar claro que, quando se fala em "golpe", a palavra se justifica apenas em função de seu aspecto retórico, mas não técnico, como bem explicitou o Min. Ricardo Lewandowski, Presidente do STF, ${ }^{13}$ em entrevista recente, ao dizer que "golpe é uma expressão que pertence ao mundo da política. E nós aqui [referindo-se ao STF] usamos apenas expressóes do mundo jurídico", uma vez que o processo de impeachment está fundado nos artigos 85 e 86 da Constituição e na Lei 1.079/1950 (e alterações posteriores), razão pela qual, sendo observados os dispositivos constitucionais e legais, não há que se falar em desrespeito ao ordenamento jurídico.

Nas acusações que envolvem o Direito Financeiro, o que se pode concluir é que os fatos descritos na denúncia ocorreram e tipificam condutas descritas como crimes de responsabilidade. Não falta base legal, nem fatos e fundamentos jurídicos na denúncia formulada. Cabe ao Congresso Nacional a palavra final sobre o reconhecimento da procedência do pedido.

\footnotetext{
A informação refere-se à época da publicação original deste texto (abril de 2016).
} 